\title{
The influence of chemical degradation and polyethylene glycol on moisture-dependent cell wall properties of archeological wooden objects: a case study of the Vasa shipwreck
}

\author{
L. Wagner ${ }^{1}$ - G. Almkvist ${ }^{2} \cdot$ T. K. Bader $^{1,3}$. \\ I. Bjurhager ${ }^{4}$ L. Rautkari ${ }^{5}$ - E. K. Gamstedt ${ }^{4}$
}

Received: 9 October 2015/Published online: 15 September 2016

(C) The Author(s) 2016. This article is published with open access at Springerlink.com

\begin{abstract}
Cell wall measures allow for direct assessment of wood modification without the adverse effect of varying density and microstructure. In this study, cell wall properties of recent and archeological oak wood from the Vasa shipwreck were investigated for cell wall stiffness, hardness and creep with respect to effects of chemical degradation, impregnation with a preservation agent, namely polyethylene glycol, and moisture. For this purpose, nanoindentation tests were performed at varying relative humidity, leading to different moisture contents in the wood samples. Concurrently, microstructural and chemical characterization of the material was conducted. Impregnated and untreated recent oak wood showed a softening effect of both moisture and preservation agent at the wood cell wall level. On the contrary, increased stiffness was found for non-impregnated Vasa oak, which can be explained by aging-related modifications in cell wall components. These effects
\end{abstract}

Electronic supplementary material The online version of this article (doi:10.1007/s00226-016-0861-x) contains supplementary material, which is available to authorized users.

L. Wagner

leopold.wagner@tuwien.ac.at

T. K. Bader

thomas.bader@lnu.se

1 Institute for Mechanics of Materials and Structures, Vienna University of Technology

(TU Wien), Karlsplatz 13/202, 1040 Vienna, Austria

2 Department of Chemistry and Biotechnology, Swedish University of Agricultural Sciences (SLU), Box 7015, 75007 Uppsala, Sweden

3 Department of Building Technology, Linnaeus University, 35195 Växjö, Sweden

4 The Ångström Laboratory, Department of Engineering Sciences, Uppsala University, Box 534, 75121 Uppsala, Sweden

5 Department of Forest Products Technology, School of Chemical Technology, Aalto University, P.O. Box 16300, 00076 Aalto, Finland 
were counteracted by the softening effect of polyethylene glycol in the impregnated Vasa material, where a lower overall stiffness was measured. The reverse effect of the preservation agent and moisture, namely increased indentation creep of the cell wall material, was revealed. The loss of acetyl groups in the hemicelluloses explained the decreased hygroscopicity of the Vasa oak. In the impregnated Vasa oak, this effect seemed to be partly counteracted by the presence of low-molecular polyethylene glycol contributing to higher hygroscopicity of the cell wall. Thus, the higher overall sorptive capacity of the impregnated Vasa material, with respect to the non-impregnated material, was detected, which has resulted in a sorptive behavior similar to that of recent oak wood. The proposed approach requires only small amounts of material, making it especially suitable for application to precious historical wooden artifacts.

\section{Introduction}

Given the structural heterogeneity of wood materials, there is naturally a large scatter in experimentally characterized mechanical properties. Especially for aged load-carrying wooden structures, it is of interest to characterize and possibly predict the deterioration of the mechanical performance of the material. Nanoindentation (NI) has established itself as a common technique to characterize local mechanical properties in the wood cell wall (Burgert and Keplinger 2013; Eder et al. 2013). Such measures can be regarded as more truly material properties, which are subject to alterations upon aging, because there is no influence of microstructural features such as the density, vessels or rays, as compared to macroscopic characterization on wood samples (Burgert et al. 2001; Gindl and Teischinger 2002). This methodology and its results were explored in a specific case of conserved waterlogged oak of a well-known museum ship with a high value for cultural heritage, where samples of macroscopic size for health monitoring are scarce.

The seventeenth century warship Vasa capsized in the Stockholm harbor during its maiden voyage. The shipwreck was raised in 1961, followed by an extensive conservation process using polyethylene glycol (PEG). This procedure aimed at replacing the water in the wood cell walls by PEG and thus preventing shrinkage and formation of cracks during drying (Håfors 2001). Since salt precipitation on numerous surfaces on the ship had been reported (Sandström et al. 2002), a series of investigations of the chemistry (Glastrup et al. 2006; Almkvist and Persson 2008a, b; Lindfors et al. 2008; Almkvist et al. 2016) and also of the mechanical properties of Vasa oak wood (Ljungdahl 2006; Bjurhager et al. 2012; Vorobyev et al. 2016) have been performed over the last years. These research activities showed that the oak wood is affected by degradation, i.e., by depolymerization of polysaccharides. Moreover, increased acidity (due to, e.g., oxalic and acetic acid) has been confirmed, resulting in decreased mechanical properties as indicated by a significant reduction in tensile strength. The degradation is more accentuated in iron-rich regions, suggesting that oxidative reactions catalyzed by iron compounds have taken place. Moreover, the impregnation agent PEG is known to have a softening effect on both archeological (Bräker and Bill 1979) and recent wood 
(Stamm 1959; Bjurhager et al. 2010). Since the hull of the Vasa shipwreck is currently mainly self-supporting, substantial loss of mechanical strength and stiffness may have a severe impact on the stability and integrity of the ship's superstructure. Furthermore, creep of the load-carrying wood members and joints results in permanent deformation of the ship structure. Treatment with PEG has also shown to have an effect on the sorption behavior of wood, and altered sorption behavior has been reported for Vasa oak material (Ljungdahl 2006; Bjurhager et al. 2012). However, the reported equilibrium moisture content (EMC) does not reflect the EMC in the cell wall, as also PEG is capable to adsorb water.

Wood exhibits a porous, heterogeneous and hierarchically organized microstructure. Therefore, it is important to take a look at lower length scales with respect to degradation, PEG treatment and moisture content, in order to gain enhanced insight into the underlying structure-function relationships. While microstructural characterization of Vasa oak wood cell walls has been performed previously (Bjurhager et al. 2012; Svedström et al. 2012), no attempts to determine micromechanical properties have been made so far. Regarding the mechanical properties of the multilayered wood cell wall, the so-called secondary layer 2 (S2 layer) and the middle lamella (ML), which connects individual wood cells, are dominating the macroscopic behavior of wood. The ML in the cell corners mainly consists of lignin and may thus be considered to behave mechanically isotropic. The S2 layer is composed of parallel cellulose fibrils embedded in a matrix of hemicellulose and lignin. The S2 layer can therefore be assumed to exhibit transverse isotropic material behavior, with the main material axes oriented parallel to the direction of the cellulose microfibrils (Salmén and Burgert 2009; Jäger et al. 2011), but inclined to the cell axis. The corresponding angle between these two directions is the socalled microfibril angle (MFA). The mechanical properties of the S2 layer and the ML can be assessed by means of NI, which has established itself as standard tool for the experimental investigation of mechanical properties of sound (Wimmer et al. 1997; Gindl et al. 2004; Wagner et al. 2013) as well as modified or degraded wood cell walls (Konnerth et al. 2010; Bader et al. 2013; Wagner et al. 2015b). The timedependent behavior of the wood cell walls can also be assessed by means of NI (Konnerth and Gindl 2006; Wagner et al. 2015a).

The aim of this study is to gain more insight into the effect of chemical degradation, conservation treatment and moisture changes on the mechanical properties of oak wood cell walls. For this purpose, NI tests were applied together with microstructural and microcompositional characterization techniques to recent and degraded, treated and untreated oak specimens. The influence of the PEG treatment on micromechanical properties of recent oak and (degraded) Vasa oak was assessed. In a first step, the investigation of non-impregnated recent oak and PEG-treated recent oak wood was expected to give insight into the effect of PEG treatment on mechanical properties of the cell wall layers. The characterization of specimens from the Vasa shipwreck with different PEG concentrations complemented the data set and allowed evaluation of the effect of PEG on the degraded archeological oak. Treatment with PEG could affect the moisture uptake in the cell walls, as PEG is believed to take the place of the water (Ljungdahl 2006; Bjurhager et al. 2012). 
The integrative evaluation of the established data set is expected to give novel insight into the moisture dependence of PEG-treated oak in general and the Vasa oak wood with different PEG concentrations in particular. Moreover, the influence of moisture content on creep deformation in the cell walls of the Vasa oak wood is expected to support the future conservation process of this unique and exceptional historic artifact. The proposed microscopic approach is general and applicable to other valuable aging wood structures.

\section{Materials and methods}

Cell wall properties of both recent oak and Vasa oak were determined by NI between 10 and $80 \%$ relative humidity. The corresponding moisture contents were measured by means of dynamic vapor sorption (DVS). The MFA of all samples, which is vital for the interpretation of the NI results in the S2 layer, was acquired by $\mathrm{X}$-ray scattering. To be able to perform chemical characterization of the small amounts of wood close to the NI indentation sites (Fig. 1), complementary spectroscopic and mass spectrometric methods were chosen. FT-IR revealed the overall composition and degradative status of the samples. The concentration of PEG as well as the condition of PEG and soluble cell wall polymers in the samples were determined by means of NMR and MALDI-TOF.

\section{Samples}

In this study, oak from the Vasa shipwreck (specimen 112-030 from block ID: 65542 , referring to the Vasa museum data bank) was used. The wood material

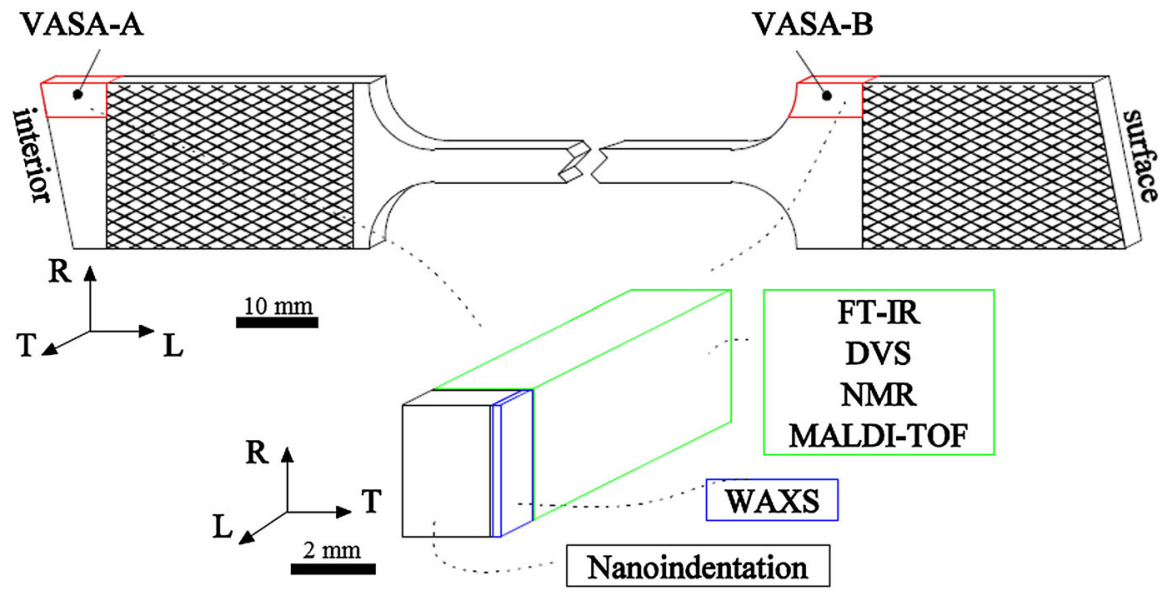

Fig. 1 Illustration of the sampling procedure for the micromechanical, microstructural and chemical analyses of the Vasa samples VASA-A and VASA-B; for extraction of the tensile specimen 112-030 from block ID 65542, see Bjurhager et al. (2012); the sampling for the references (REF-1, REF-1-PEG) was performed in a similar way; for abbreviations, see the "Materials and methods" section 
Table 1 Results from WAXS, NMR and MALDI-TOF MS analyses

\begin{tabular}{lllllll}
\hline Sample & $\begin{array}{l}\text { Depth } \\
\text { from } \\
\text { surface } \\
(\mathrm{mm})\end{array}$ & $\begin{array}{l}\text { MFA } \\
\left({ }^{\circ}\right)\end{array}$ & $\begin{array}{l}\text { PEG } \\
\text { content } \\
(\%)\end{array}$ & $\begin{array}{l}\text { Average } \\
\text { molecular weight } \\
\text { of PEG } M_{\mathrm{w}} \\
\left(\mathrm{g} \mathrm{mol}^{-1}\right)\end{array}$ & $\begin{array}{l}\text { Molecular weight } \\
\text { distribution of } \\
\mathrm{PEG}^{\mathrm{a}}\left(\mathrm{g} \mathrm{mol}^{-1}\right)\end{array}$ & $\begin{array}{l}\text { Water-soluble } \\
\text { carbohydrates } \\
\left(\mathrm{mg} \mathrm{g}^{-1}\right)\end{array}$ \\
\hline VASA-A & 170 & 17.6 & $<0.1$ & - & - & 80 \\
VASA-B & 36 & 17.6 & 10.4 & 350 & $200-1000$ & n.d. \\
REF-1 & - & 13.7 & 0 & - & - & $14^{\mathrm{b}}$ \\
REF-1-PEG & - & 15.6 & 17 & 620 & $400-1000$ & n.d. \\
REF-2 & - & 12.0 & 0 & - & - & $14^{\mathrm{b}}$ \\
\hline
\end{tabular}

n.d. not detectable due to overlapping signals with PEG

a See supplementary material, S1

b According to Willför et al. (2005)

originated from tensile test specimens analyzed in a previous study (Bjurhager et al. 2012). A gradient of the PEG content from the surface to the interior of the Vasa oak has been reported (Håfors 2001), which also was the case for this object (Bjurhager et al. 2012). Two samples were prepared with different depth from the original surface (Table 1) to achieve one sample with very low content of PEG (VASA-A) and another sample with intermediate content of PEG (VASA-B). These samples were matched in the longitudinal direction, in order to minimize microstructural variability in the radial and tangential directions (Fig. 1). In addition, three reference samples of recent oak (Quercus robur L.) were used: untreated recent oak (REF-1 and REF-2) and recent oak impregnated with PEG600 (38 \% w/w) (REF-1$\mathrm{PEG})$. Material from these three samples had been used as reference material in previous studies (Bjurhager et al. 2010, 2012; Wagner et al. 2015a). All subsamples used for micromechanical and micromorphological characterization, spectroscopic and chemical analyses, as described below, were taken within a narrow region (Fig. 1) in order to reliably interpret and compare the results.

\section{Micromechanical characterization: nanoindentation tests}

For the NI tests, samples of approximately $1 \times 1 \times 1 \mathrm{~mm}^{3}(L \times R \times T)$ were cut from the initial specimens. All samples were embedded in an epoxy resin (Agar Low Viscosity Resin Kit, Agar Scientific, UK) to facilitate the handling of the small wood cubes during sample preparation. The epoxy resin was subsequently found inside the vessels and ray cells via visual inspection but apparently had not penetrated into the fiber lumina. The translucent nature of the embedding resin allowed checking the local fiber orientation using a light microscope. A plane surface perpendicular to the local fiber axis was cut smooth with a microtome (Leica Ultracut, Leica Microsystems, GER), equipped with a diamond knife (Wagner et al. 2014). NI tests were performed using a TriboIndenter ${ }^{\circledR}$ (Hysitron Inc., USA) at different controlled climatic conditions, using a RH-200 Relative Humidity Generator (L\&C Science and Technology, USA). The tests were performed in two separate experimental campaigns. On the first set of samples (VASA-A, REF-1, 
REF-1-PEG), tests were performed in load control, at 30 and $60 \% \mathrm{RH} / 22{ }^{\circ} \mathrm{C}$, using a one-step load function including a holding phase of $30 \mathrm{~s}$ and loading and unloading rates of $50 \mu \mathrm{N} / \mathrm{s}$, where the maximum loads amounted to 250 and $150 \mu \mathrm{N}$ for the S2 layer and the ML, respectively. The second set of samples (VASA-B, REF-2) was tested together with samples from a different study (Wagner et al. 2015a), where two-step load functions-also load controlled and with two $15 \mathrm{~s}$ holding phases and loading and (partial) unloading rates of $50 \mu \mathrm{N} / \mathrm{s}$ - with peak loads of 200 and $150 \mu \mathrm{N}$ for S2 layer and ML, respectively, were used. These tests were performed at a broader range of climatic conditions, i.e., at 10, 40, 60 and $80 \% \mathrm{RH} / 22{ }^{\circ} \mathrm{C}$, as well as in saturated conditions under water. All samples were climatized inside the TriboIndenter ${ }^{\circledR}$ at the desired $\mathrm{RH}$ over night before the actual tests. Prior to mechanical testing, samples were stored at environmental conditions of $22^{\circ} \mathrm{C}$ and a RH between 30 and $40 \%$. RH was increased and reduced from this reference point for mechanical testing above and below $40 \% \mathrm{RH}$, respectively. Reduced peak loads of $130 \mu \mathrm{N}$ and $90 \mu \mathrm{N}$ were used for the measurements at $20{ }^{\circ} \mathrm{C} / 80 \% \mathrm{RH}$ and under water, respectively. The reason for this reduction-as well as for the difference in maximum loads for the S2 layer and the CCML-lies in the different mechanical properties of the cell wall layers and the expected softening of the cell wall material, which would have resulted in considerable differences in penetration depths impeding the comparison of test results. All indents were placed in the center of each sample, where the embedding resin had apparently not penetrated into the fiber lumina. A total number of 15-20 indents were performed in the S2 layers of fibers and 8-10 indents in the ML in each investigated sample at the respective temperature/humidity conditions. Indents in the S2 layer were placed at different cells with different positions as regards the cell wall orientation, in order to reduce effects of sample or local fiber disorientation (Konnerth et al. 2009). While the S2 layer usually exhibits sufficient thickness for NI, the ML is only accessible in the cell corners (Wimmer et al. 1997; Wagner et al. 2013). All indents were inspected by an inbuilt scanning probe microscope to verify that the indents in the S2 layer and the cell corner middle lamella (CCML) had been placed correctly. The indentation modulus $M$ and hardness $H$ were evaluated from the maximum force $F_{\text {max }}$, the initial unloading stiffness $S$ and the contact area $A_{\mathrm{C}}$ according to Oliver and Pharr (1992):

$$
\begin{gathered}
M=\frac{\sqrt{\pi} S}{2 \sqrt{A_{\mathrm{C}}}}, \\
H=\frac{F_{\max }}{A_{\mathrm{C}}},
\end{gathered}
$$

with $A_{\mathrm{C}}$ as the projected contact area, evaluated from a calibrated tip area-penetration depth function (Oliver and Pharr 1992). In addition, a measure for the timedependent deformation underneath the indenter tip, the indentation creep $C$, was calculated as

$$
C=\frac{h_{1}-h_{0}}{h_{0}} \times 100 \%,
$$


with $h_{0}$ and $h_{1}$ as the indentation depths at the beginning and at the end of the holding phase, respectively (CSM Instruments 2002). The respective load functions were different for the two described sets of experiments. To be able to compare $C$ between all samples, it was evaluated for the second 15-s holding phase for VASA-B and REF-2 (two-step load function) and for the first $15 \mathrm{~s}$ of the $30-\mathrm{s}$ holding phase for VASA-A, REF-1 and REF-1-PEG (one-step load function). The indentation depths at half and maximum loads were in a range where no depth effects on $M$ and $H$ emerge from the experimental scatter (Tze et al. 2007; Wagner et al. 2014). Thus, $M$ and $H$ were evaluated at half and maximum load together.

\section{Microstructural characterization: wide-angle X-ray scattering (WAXS)}

From each wood specimen, one tangential thin section of $200 \mu \mathrm{m}$ thickness, originating from the same location (i.e., within the same annual ring) as the samples for NI (Fig. 1), was taken and used for the determination of the microfibril angle (MFA). The MFA was determined from these thin sections by means of wide-angle X-ray scattering (WAXS). A Bruker Nanostar device (Bruker AXS, USA), working with $\mathrm{CuK}_{\alpha}$ radiation (wavelength $1.54 \AA$ ), was used to collect the $2 \mathrm{D}$ diffraction patterns at a distance of $11.2 \mathrm{~cm}$ for $30 \mathrm{~min}$. The resulting intensities from the diffraction patterns were integrated and processed according to Meylan (1967), to determine the specimen-specific MFA.

\section{Cell wall composition: chemical analyses and FT-IR}

Samples for nuclear magnetic resonance (NMR) spectroscopy and mass spectroscopy (MS), using matrix-assisted laser desorption/ionization time-of-flight (MALDI-TOF), were prepared from a $5 \times 5 \mathrm{~mm}^{2}$ subsample taken from a nearby position within the original specimens, where the samples for NI had previously been prepared (Fig. 1). These subsamples were manually fragmented to $<1 \mathrm{~mm}$. Extracts for MS and NMR were prepared by extracting $50 \mathrm{mg}$ of sample material in $1.5 \mathrm{ml} \mathrm{D} 2 \mathrm{O}$ for 2 days.

The concentration of the PEG of VASA-A, VASA-B and REF-1-PEG was determined in aqueous extracts $\left(\mathrm{D}_{2} \mathrm{O}\right)$ by quantitative H-NMR (Pauli et al. 2005). Twenty microliters of a $30 \mathrm{mM}$ solution of sodium 3-(trimethylsilyl)propanoate-d4 (TMSP) (Cambridge Laboratories, UK) was added as a reference to the extracts $(600 \mu \mathrm{l})$. The NMR data were recorded at $30{ }^{\circ} \mathrm{C}$ on a Bruker DRX600 NMR (Bruker Daltonik, Germany). Baseline correction, phasing and peak integration were applied manually. The concentration of PEG and xylan was quantified by comparing the relative intensities of PEG signal ( $\delta 3.70)$ or xylan signals $(\delta 3.1-4.6)$ with the TMSP signal $(\delta 0.00)$. For details and instrument parameters, see Almkvist and Persson (2008b). The ratio between terminal and bulk methylene protons in PEG provides an accurate estimation of the average molecular mass of the polymer.

For MALDI-TOF, the aliquot of the prepared $\mathrm{D}_{2} \mathrm{O}$ solutions above was mixed (1:1) with the matrix [0.1 M 2,5-dihydroxybenzoic acid (Fluka) in 1:1 methanol/ water]. The analysis of the polymer distribution of PEG was performed in the range of $m / z, 160-4500$ using a Bruker Reflex ${ }^{\mathrm{TM}}$ III mass spectrometer (Bruker Daltonik, 
Germany) operated in delayed extraction mode with an acceleration voltage of $20 \mathrm{kV}$ and a reflector voltage of $23 \mathrm{kV}$. The laser power was adjusted to a level slightly above the threshold for the formation of observable ions. For each sample, the results from 100 shots were summarized.

Subsamples $(20 \mathrm{mg})$ for FT-IR analyses were prepared from samples VASA-A, VASA-B, REF-1 and REF-1-PEG. The samples were gently filed by hand to a size of approx. $0.1 \mathrm{~mm}$ and then placed in a desiccator with phosphorus pentoxide (Sigma-Aldrich Co., USA) as a drying agent. Two-milligram dry material was ground with $200 \mathrm{mg}$ oven dried potassium bromide (KBr) (Sigma-Aldrich Co., USA), and two pellets were prepared for each sample. As a complement, VASA-B was pre-extracted in water to remove PEG before drying. Infrared spectra were obtained with a Spectrum 100 FT-IR Spectrometer (PerkinElmer, USA) equipped with a lithium tantalite $\left(\mathrm{LiTaO}_{3}\right)$ detector. The instrument was adjusted to an iris of $8.94 \mathrm{~mm}$, and 32 scans with a scan range between 4000 and $400 \mathrm{~cm}^{-1}$ were collected with a resolution of $4 \mathrm{~cm}^{-1}$. The background of $\mathrm{KBr}$ pellets was subtracted for each analyzed sample, and the acquired data of the two wood-KBr pellets were averaged. The FT-IR spectra were baseline-corrected by applying a spline function where the absorbance was set to zero at 3600, 2400, 1900, 800 and $400 \mathrm{~cm}^{-1}$ for all spectra.

\section{Quantification of moisture content: dynamic vapor sorption}

The EMC at the set RH was analyzed at the set RH from small matched wood samples (Fig. 1) of approximately $10 \mathrm{mg}$, which were prepared using a razor blade. The analyses were performed using a DVS intrinsic apparatus (Surface Measurement Systems, UK). First, the samples were dried under a dry nitrogen gas flow (100 sccm) until MC $0 \%$, followed by a sorption cycle with $10 \% \mathrm{RH}$ steps from 0 to $90 \%$ (sorption) and from 90 to $0 \%$ (desorption) at $22{ }^{\circ} \mathrm{C}$. The DVS intrinsic apparatus maintained a constant $\mathrm{RH}$ until the change in the sample mass was lower than $0.001 \% / \mathrm{min}$ over a $10-\mathrm{min}$ period to ensure a constant equilibrium condition after each RH step. Since the samples were not extracted before the DVS measurements, the EMC for VASA-A, VASA-B and REF-1-PEG are based on the total mass of wood cell walls and PEG.

\section{Results and discussion}

\section{Microfibril angle, moisture content and compositional characteristics}

The MFA is vital for interpreting and comparing the NI results of the S2 layer of wood. WAXS measurements revealed the average MFA in EW and LW of each sample (see Table 1). Taking the size of the beam spot on the sample of $0.5 \mathrm{~mm}$, as well as the thickness of the section into account, the resulting MFA represents an average over only 30-50 tracheids of either EW or LW. The average MFA of VASA $\left(17.6^{\circ}\right)$ lied within the range of reported MFAs for samples from the same block of Vasa material (Bjurhager et al. 2012; Svedström et al. 2012). 
NMR and MALDI-TOF were used to provide important information concerning PEG content and molecular weight $\left(M_{\mathrm{w}}\right)$ and distribution of PEG, and also information about depolymerization of hemicelluloses. The measurements, summarized in Table 1, revealed a negligible PEG content in VASA-A. For VASA-B, the $M_{\mathrm{w}}$ and molecular weight distribution of PEG were lower as compared to REF1-PEG (treated with PEG600) and to the PEG originally used during the conservation treatment of the Vasa, i.e., mainly PEG600 and PEG1500 (Håfors 2001). The results are in line with previous studies, which show that PEG often has a decreased $M_{\mathrm{w}}$ below the surface region, particularly in chemically degraded areas (Almkvist and Persson 2008b). Effects of reduced $M_{\mathrm{w}}$ of PEG on moisture content and mechanical properties of PEG-treated wood are discussed further below. The significantly increased content of soluble carbohydrates in VASA-A compared to the recent oak (Table 1) shows that this sample is a typical Vasa sample in which hemicelluloses have undergone depolymerization (Almkvist and Persson2008b). This was further supported by the presence of signals of low-molecular oligomers in the MALDI-TOF MS spectra (see S1) with a mass difference of $132 \mu$ corresponding to depolymerized xylan (Almkvist and Persson 2008a).

The FT-IR spectra of VASA-A, VASA-B and REF-1 are shown in Fig. 2. The fingerprint region (1800-900 $\mathrm{cm}^{-1}$ ) contains the characteristic bands from unconjugated carbonyl $(\mathrm{C}=\mathrm{O})$ stretch at $1742 \mathrm{~cm}^{-1}$ (acetyl groups attached to xylan), aromatic skeletal vibration at 1506 and $1595 \mathrm{~cm}^{-1}$ (lignin), signals related to $\mathrm{C}-\mathrm{H}$

Fig. 2 FT-IR spectra of VASA$A, V A S A-B$ (extracted), $R E F-1$ and $R E F-1-P E G$




deformation in the region $1500-1300 \mathrm{~cm}^{-1}$ (hemicellulose/cellulose), C-O-C vibrations in the region $1300-900 \mathrm{~cm}^{-1}$ (hemicellulose/cellulose) (Moore and Owen 2001). The spectrum of recent oak impregnated with PEG (REF-1-PEG) displayed, as expected, strong additional signals at 1100,1250 and $1350 \mathrm{~cm}^{-1}$ originating from PEG (Fig. 2). Therefore, VASA-B (containing PEG, Table 1) was pre-extracted in order to avoid interference from PEG in the spectrum (Fig. 2).

Both VASA-A and VASA-B displayed significantly decreased signal intensity from the acetyl group on xylan $\left(1742 \mathrm{~cm}^{-1}\right)$. This change was also accompanied by reduced intensity of the signal at $1242 \mathrm{~cm}^{-1}$ assigned to $\mathrm{C}-\mathrm{O}-\mathrm{R}$ in the acetyl group (Marchessault 1962). The effect was most prominent for VASA-A indicating a more severe deacetylation due to acid hydrolysis in this sample. Furthermore, new and partly diffused signals appeared at $1700 \mathrm{~cm}^{-1}$, a region typical for carboxylic acid $(\mathrm{C}=\mathrm{O})$ vibrations. The result indicates that oxidative degradation has taken place in terms of an increased number of carboxylic groups bound to the wood polymers (Almkvist et al. 2016).

Despite the changed intensities of the bands pointed out above, the investigated samples displayed intensities at the same level in the region $1600-1300 \mathrm{~cm}^{-1}$, which includes signals from lignin, xylan and cellulose. This fact indicates that no significant changes have taken place in terms of relative composition of the major wood polymers in the Vasa samples as compared to recent oak. The variation in intensity of the strong signals around $1100 \mathrm{~cm}^{-1}$ could be an effect of sample preparation since it is sensitive for particle size in the FT-IR samples (Faix and Böttcher 1992). From the NMR and MS results in the current and previous studies, it is evident that xylan has been partly depolymerized making it water soluble in chemically degraded Vasa oak, here represented by VASA-A. This could be a result of oxidative degradation or acid hydrolysis, or a combination of these reactions. As a result of increased acidity, this sample had also lost most of its original acetyl groups previously attached to xylan.

The EMC was determined by DVS for each sample at the corresponding RH, prevailing during mechanical measurements (see Table 2). However, the reported EMC figures have to be considered as EMC for the whole wood samples, i.e., including PEG. Moreover, the actual EMC in the S2 layer and the CCML might slightly differ from these overall values, due to their different chemical composition (Smith and Langrish 2008). PEG600 has been shown to be more hygroscopic than oak wood cell walls in the lower $\mathrm{RH}$ regime. At higher $\mathrm{RH}$, this trend is reversed (Ljungdahl 2006; Bjurhager et al. 2010). This is expected to be the reason for the differences in EMC between the REF-1-PEG and REF-1 sample, an observation that has been made before (Bjurhager et al. 2010).

The moisture content is slightly higher in VASA-B than in VASA-A over the whole RH range. There are two explanations: VASA-A and VASA-B have to some extent lost their acetyl groups which make them less hydroscopic, and VASA-B contains PEG that increases the MC. This is in contrast to the differences between the reference oak and REF-1-PEG, where the PEG treatment was found to slightly reduce the overall $\mathrm{MC}$ in the lower $\mathrm{RH}$ regime and to increase the $\mathrm{MC}$ only at higher RH. It has to be kept in mind that the PEG in VASA-B has undergone 
Table 2 EMC at different $\mathrm{RH}$ for all samples
${ }^{a}$ EMC values for VASA-B and REF-1-PEG have to be considered as EMC for whole samples, i.e., wood + PEG

\begin{tabular}{lccccc}
\hline RH $(\%)$ & 10 & 30 & 40 & 60 & 80 \\
\hline $\begin{array}{l}\text { VASA-A (interior) } \\
\text { Sorption }\end{array}$ & 1.7 & 4.3 & 5.3 & 6.6 & 9.9 \\
$\begin{array}{l}\text { Desorption } \\
\text { VASA-B (surface) }\end{array}$ & 2.4 & 5.7 & 7.0 & 9.7 & 13.6 \\
$\begin{array}{l}\text { Sorption } \\
\text { aesorption }\end{array}$ & 1.9 & 4.5 & 5.6 & 7.6 & 11.6 \\
REF-1 & 3.0 & 6.3 & 7.7 & 10.6 & 15.0 \\
Sorption & 1.4 & 4.0 & 5.2 & 7.4 & 11.5 \\
Desorption & 2.6 & 6.0 & 7.7 & 10.9 & 14.2 \\
REF-2 & & & & & \\
Sorption & 2.4 & - & 5.6 & 6.8 & 11.7 \\
$\quad$ Desorption & - & - & - & - & - \\
REF-1-PEG & & & & & \\
Sorption & 0.8 & 2.8 & 4.0 & 7.0 & 14.4 \\
Desorption & 1.0 & 3.2 & 4.5 & 8.0 & 14.9 \\
\hline
\end{tabular}

depolymerization, represented by a lower $M_{\mathrm{w}}$ (Table $1 ; \mathrm{S} 1$ ), making the PEG in VASA-B even more hygroscopic.

\section{Micromechanical characteristics}

NI resulted in indentation moduli $M$, indentation hardness $H$ and indentation creep $C$ of the REF-1-PEG, REF-1 and REF-2 samples at different RH. Results of NI tests are summarized in Tables 3 and 4 and illustrated in Figs. 3 and 4 . Before mechanical testing, samples were stored at environmental conditions of $22^{\circ} \mathrm{C}$ and a RH between 30 and $40 \%$. Thus, the EMC in Figs. 3 and 4 for RH below $40 \%$ corresponds to values from the desorption curve of the measured sorption isotherms (Table 2), while for $\mathrm{RH} \geq 40 \%$ the EMC corresponds to the values from the sorption curves. At $20{ }^{\circ} \mathrm{C} / 60 \% \mathrm{RH}, M$ and $H$ in the S2 layer and the CCML of REF1 and REF-2 lie within previously reported values for European oak with comparable MFA (Bader et al. 2013; de Borst et al. 2012). As mentioned before, the reported EMC values have to be considered as EMC values for whole wood samples, i.e., not considering differences between the EMC in the S2 layer, the CCML and the PEG in the cell lumina of the impregnated samples.

Assuming isotropic behavior of the CCML, $M$ and $H$ are directly linked to the mechanical properties of the material. Thus, $M$ and $H$ in the CCML can be directly compared between samples to elucidate the effects of different treatments and/or degradation. On the contrary, $M$ of the S2 layer is not only dependent on the inherent material properties of this layer, but also on the direction of the main material axes with respect to the indentation direction, i.e., the MFA, and the degree of anisotropy (Jäger et al. 2011). On the other hand, $H$ of the S2 layer has been experimentally shown to be insensitive to the MFA (Wimmer et al. 1997; Gindl 


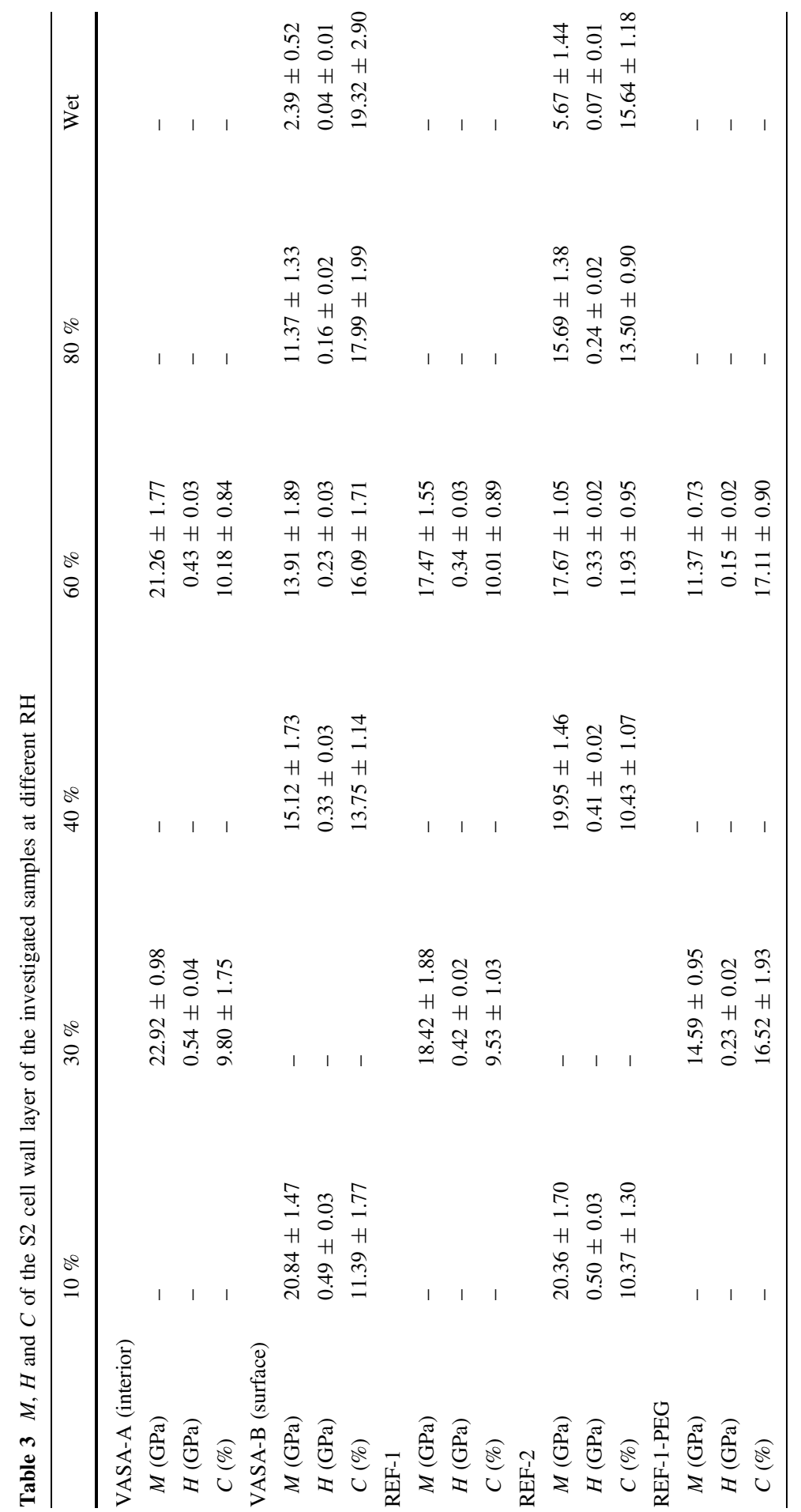




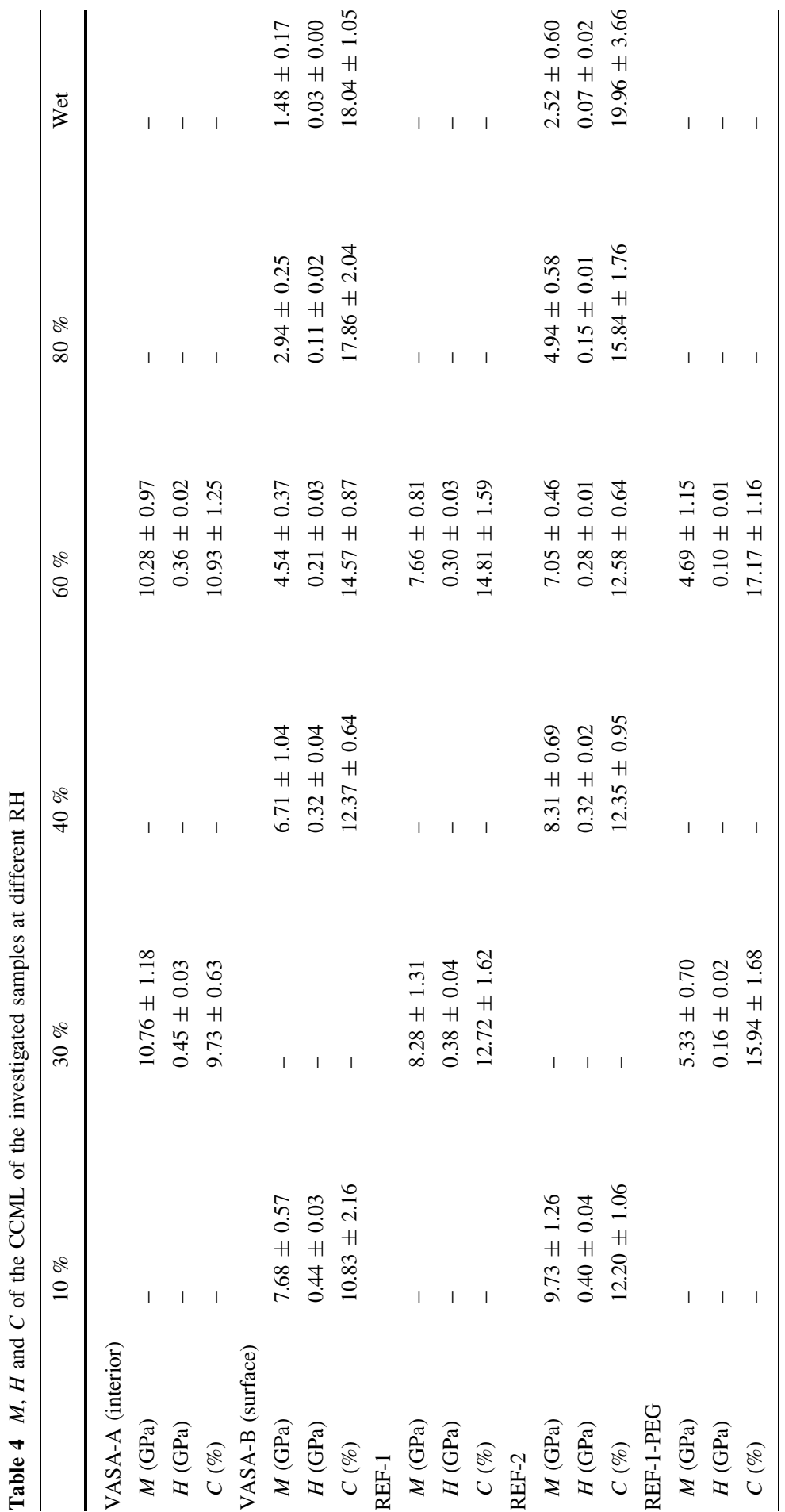



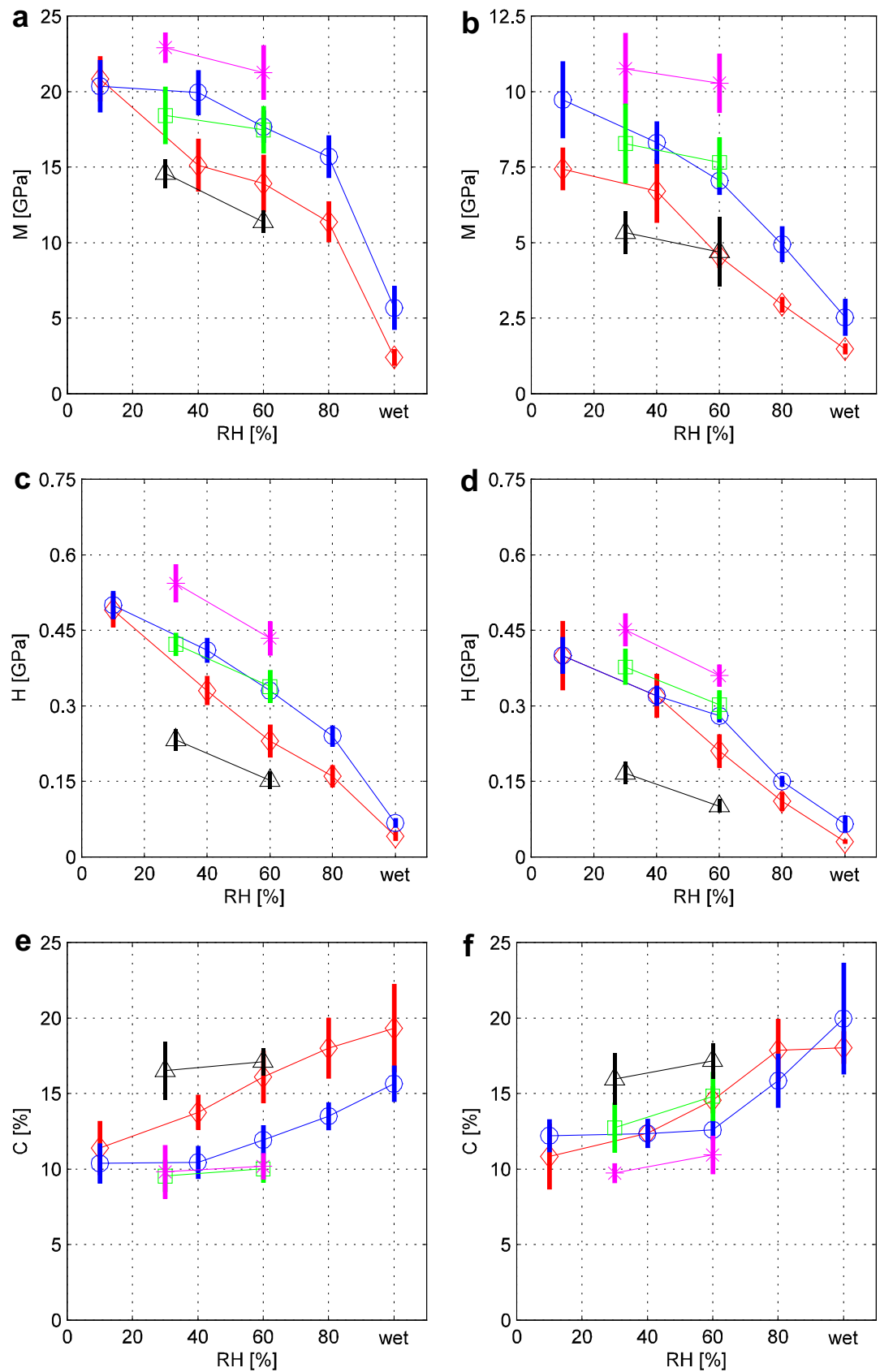

Fig. 3 Humidity dependence of the S2 layer (a, c, e) and CCML (b, d, f); star symbol VASA-A, diamond symbol VASA-B, triangle REF-1-PEG, square REF-1, circle REF-2, vertical lines represent $\pm \mathrm{SD}$ 



Fig. 4 Moisture dependence of the S2 layer (a, c, e) and CCML (b, d, f); star symbol VASA-A, diamond symbol VASA-B, triangle REF-1-PEG, square REF-1, circle REF-2, vertical lines represent $\pm \mathrm{SD}$; the MC of VASA-B and REF-1-PEG has to be considered as MC for the whole sample, i.e., for wood + PEG 
et al. 2004; Tze et al. 2007). Thus, in the S2 layer, $H$ can be directly compared between specimens, while for the comparison of $M$, the MFA will have to be taken into account. The difference in MFA (maximum $5.6^{\circ}$ ) between the investigated samples (Table 1) could cause a difference in the indentation modulus between the samples of up to about $10 \%$ (Jäger et al. 2011). In the following, NI results will be discussed with respect to the treatment with PEG, the EMC and the chemical composition described before.

\section{Influence of PEG treatment on mechanical properties of oak cell walls}

The influence of PEG on micromechanical properties of oak cell walls can be elucidated by comparing test results of the samples REF-1 and REF-1-PEG (Tables 3, 4), which showed rather similar MFAs (Table 1). Only minor differences were observed between REF- 1 and REF-2 at $20{ }^{\circ} \mathrm{C} / 60 \% \mathrm{RH}$. The PEG treatment of recent oak resulted in a decrease in $M$ and $H$ as well as an increase in $C$ in the S2 layer and CCML, respectively. Decreased macroscopic stiffness upon impregnation with PEG has been reported previously by Bjurhager et al. (2010). A recent study by Vorobyev et al. (2016) investigated the combined effect of aging and impregnation of PEG in Vasa oak on the macroscopic elastic properties as compared with the case of recent oak and found that all Young's moduli and shear moduli along the principal material axes were lower for the Vasa material. For wood with comparable densities and microfibril angles, cell wall softening correlates with an associated softening of the wood on the macroscopic scale (e.g., Gibson et al. 2010).

Regarding the PEG treatment of recent oak, $M$ and $H$ of the S2 layer and the CCML were reduced by 35 and 38 and 56 and $67 \%$, respectively (Table 3). At the same time, $C$ of the S2 layer and the CCML increased by 71 and $16 \%$ (Table 3). Thus, a similar effect of the PEG treatment on $M$ and $H$ of the S2 layer and the CCML was observed. In contrast to $M$ and $H$, the effect of PEG on C was higher in the S2 layer than in the CCML, shown by an increase in $C$ of 71 and $16 \%$ for S2 layer and CCML, respectively. This emphasizes the strong softening effect of PEG, which consequently has penetrated into the wood cell walls. There it is known to act as a softening plasticizer, breaking secondary hydrogen bonds between the cell wall polymers (Hoffmann 1988; Wallström and Lindberg 1995). Due to short holding times and variations in indentation forces, the measured indentation creep values cannot be regarded as material parameters to the same extent as $M$ and $H$. Although rheological material parameters can be identified from NI curves in isotropic substrates (Jäger et al. 2007; Chen and Diebels 2013), the viscoelastic anisotropic nature of the wood cell wall requires substantially more experimental data in different indentation directions and modeling work to characterize the creep material behavior. Nevertheless, the presented indentation creep data can be used for qualitative comparisons between the tested samples.

A reduction of EMC by reducing the RH to $30 \%$ reduced the effect of the PEG treatment with respect to $M$ and $H$, but still resulted in lower $M$ and $H$ of the PEGtreated wood compared to recent oak. The corresponding losses amounted to 21 and $36 \%$ for the modulus and 45 and $58 \%$ for the hardness of the S2 layer and the CCML, respectively. The reduction of $\mathrm{RH}$ to $30 \%$, however, leads to a slight 
increase in the influence of PEG on $C$. The decreases compared to the reference material were 73 and $25 \%$ for the S2 layer and the CCML, respectively. Changes in micromechanical properties between different EMC of the two samples indicate that a considerable part of the softening can be attributed to the penetration of PEG into the cell wall, while the influence of the EMC was in the same range as compared between the two samples.

\section{Micromechanical properties of Vasa oak cell walls}

The two Vasa samples are clearly distinguished from each other in terms of their micromechanical properties. The values for $M$ and $H$ of the S2 layer and the CCML of the PEG-free VASA-A specimen were even slightly above those of REF-1 and REF-2. Several phenomena may deliver explanations for this finding. The degradation of xylan, having partly lost its acetyl side-groups, can lead to parts of the xylan fraction being more tightly bound to the cellulose chains (Kabel et al. 2007) and thus potentially increases the cell wall stiffness. Possible other effects related to physical aging of wood and other cellulose-based products are fibril aggregation by the formation of new hydrogen bonds, increased cellulose crystallinity due to degradation of amorphous cellulose, as well as additional cross-linking of cell wall polymers (Kato and Cameron 1999; Zervos 2010). These phenomena might have contributed to the observed stiffness increase as well. Higher $M$ and $H$ values in the S2 layer and CCML of degraded oak samples have previously been reported for material of the Oseberg shipwreck, an ancient Viking ship (Bader et al. 2013), which displayed a complete deacetylation. Deacetylation is a natural, slow process that affects all wood upon aging but is considerably accelerated in the presence of acids (Fengel and Wegener 2003). However, the Oseberg ship displayed severe microbial degradation of the wood since it was buried in soil for a long time.

The second Vasa specimen VASA-B showed $M$ and $H$ values well below the values of VASA-A (Tables 3, 4). A dominant difference between these samples is their PEG content (Table 1). The reduction of $M$ and $H$ by PEG impregnation from VASA-A to VASA-B was similar to the differences between the reference samples, as discussed above, i.e., 35 and $56 \%$ for $M$ and 47 and $42 \%$ for $H$, for the S2 layer and the CCML, respectively.

Test data related to time-dependent deformations of the cell wall during NI were also well in line with the phenomena discussed above. Due to the high PEG content, creep deformations were higher in VASA-B than in VASA-A. The latter showed creep deformations even smaller than the reference oak. This might again be a result of the degradation of xylan, being more tightly bound to the cellulose chains (Kabel et al. 2007) and thus potentially also decreasing the creep deformations in the wood cell wall.

The PEG treatment of recent oak led to lower values of $M$ and $H$ and higher values of $C$ compared to the PEG-treated Vasa oak sample (VASA-B). This illustrates the strong dependence of the micromechanical properties on the PEG content (cf. Table 1) and supports previous experimental investigations on macroscopic samples that highlighted a higher creep activity of PEG-treated 
archeological oak compared to recent oak (Hoffmann 2010). The difference between degraded and non-degraded samples is similar for PEG-free and PEGimpregnated conditions.

The softening behavior of the S2 layer and the CCML of all samples with increasing $\mathrm{MC}$ can be described by S-shaped curves, as reported for macroscopic stiffness and strength of wood (Gerhards 1982) as well as for cell wall properties, i.e., $M, H$ and $C$ (Wagner et al. 2015a). Figure 4 shows the test results of the experimental study over the overall moisture content of the samples. However, only parts of the whole S-shaped curve can be seen, since MCs between $12 \%$ and FSP have not been measured. The results of the samples without PEG, i.e., VASA-A, REF-1, and REF-2, follow closely the above described trend. As for PEGimpregnated samples, i.e., VASA-B and REF-1-PEG, their behavior might be described by a similar S-shaped curve but shifted toward lower MCs. This would well describe the softening effect of the PEG in addition to the softening effect of the absorbed water in the cell wall, but would mean that a saturation limit is reached at lower MC as compared to untreated recent oak wood. It has to be kept in mind that the results for $80 \% \mathrm{RH}$ and saturated conditions have been obtained using lower maximum loads. Thus, $C$ at these conditions represents creep at a lower load level. For the same load levels used at 10-60\%RH, $C$ would be even higher.

For the preservation of future archeological findings of waterlogged wooden artifacts, less softening of the wood cell walls by using a different preservation agent would be desirable. From a purely structural viewpoint, a reduction in RH in the museum would reduce the ongoing deformation of the Vasa ship, but this is more costly to maintain and might cause further cracking from drying of the wood material.

\section{Conclusion}

In this study, the influence of two characteristics on the mechanical softening of wood cell walls, namely the effect of a conservation agent (PEG) and the effect of moisture, has been studied by means of a micromechanical approach. The investigations covered recent oak wood-in native condition as well as impregnated with PEG-and archeological, chemically degraded and partly PEG-treated wood samples from the Vasa shipwreck.

Wood cell walls containing PEG generally showed lower stiffness and indentation hardness as well as higher creep deformations than the untreated reference samples. Hence, PEG can be considered a softening agent in the wood cell walls. The differences between the PEG-treated Vasa and the PEG-free Vasa oak wood follow closely the effect encountered for PEG impregnation of recent oak.

The investigations revealed that the overall moisture sensitivity of the wood cell wall was similar to the general behavior of wood at the macroscopic scale, namely a decrease in stiffness and indentation hardness together with increased creep deformations. The sensitivity was higher for the samples containing PEG, as compared to untreated wood. These findings are based on the calculation of the overall EMC of the wood samples, related to the dry mass of wood and PEG. Future 
work could focus on the investigation of local moisture variations within the cell wall layers and their relation to the degradation and impregnation. This would considerably enhance also the understanding of structure-mechanics relationships.

The PEG-free Vasa sample showed slightly higher stiffness and indentation hardness as well as lower creep deformations as compared to the reference samples. Although this phenomenon of increased mechanical properties for degraded wood has been reported before, the exact reason for this finding currently remains unknown. Possible explanations might be found in previously reported aging-related effects on the microstructure, for example deacetylation of xylan increased crosslinking and cellulose crystallinity or a loss of hygroscopicity due to a loss of acetyl groups of xylan.

The observed correlation between macroscopic softening and the underlying softening on the cell wall level supports the applicability of NI to monitor such effects on archeological wood. Furthermore, only small samples are required compared with tensile testing of solid wood, highlighting the potential of nanoindentation to screen the mechanical health of precious archeological wood.

Acknowledgments Open access funding provided by TU Wien (TUW). The authors would like to thank H. Peterlik (University of Vienna, Austria) for providing access to the WAXS equipment. C. Bos (currently Karlsruhe Institute of Technology, Germany) is thanked for performing a part of the nanoindentation tests.

Open Access This article is distributed under the terms of the Creative Commons Attribution 4.0 International License (http://creativecommons.org/licenses/by/4.0/), which permits unrestricted use, distribution, and reproduction in any medium, provided you give appropriate credit to the original author(s) and the source, provide a link to the Creative Commons license, and indicate if changes were made.

\section{References}

Almkvist G, Persson I (2008a) Analysis of acids and degradation products related to iron and sulfur in the Swedish warship Vasa. Holzforschung 62:694-702

Almkvist G, Persson I (2008b) Degradation of polyethylene glycol and hemicellulose in the Vasa. Holzforschung 62:64-70

Almkvist G, Norbakhsh S, Bjurhager I, Varmuza K (2016) Prediction of tensile strength in ironcontaminated archaeological wood by FT-IR spectroscopy-a study of degradation in recent oak and Vasa oak. Holzforschung. doi:10.1515/hf-2015-0223

Bader TK, de Borst K, Fackler K, Ters T, Braovac S (2013) A nano to macroscale study on structuremechanics relationships of archaeological oak. J Cult Herit 14(5):377-388

Bjurhager I, Ljungdahl J, Wallström L, Gamstedt EK, Berglund LA (2010) Towards improved understanding of PEG-impregnated waterlogged archaeological wood: a model study on recent oak. Holzforschung 64:243-250

Bjurhager I, Halonen H, Lindfors EL, Iversen T, Almkvist G, Gamstedt EK, Berglund LA (2012) State of degradation in archeological oak from the 17th century Vasa ship: substantial strength loss correlates with reduction in (holo)cellulose molecular weight. Biomacromolecules 13(8):2521-2527

Bräker OU, Bill J (1979) Zum derzeitigen Stand der Nassholzkonservierung (The present status of wetwood conservation). Z Schweiz Archäol Kunstgesch 36:97-145 (in German)

Burgert I, Keplinger T (2013) Plant micro- and nano-mechanics: experimental techniques for plant cellwall analysis. J Exp Bot 64:4635-4649

Burgert I, Bernasconi A, Niklas KJ, Eckstein D (2001) The influence of rays on the transverse elastic anisotropy in green wood of deciduous trees. Holzforschung 55:449-454 
Chen Z, Diebels S (2013) Parameter re-identification in nanoindentation problems of viscoelastic polymer layers: small deformation. ZAMM 93:88-101

de Borst K, Bader TK, Wikete C (2012) Microstructure-stiffness relationships of ten European and tropical hardwoods species. J Struct Biol 177:532-542

Eder M, Arnould O, Dunlop JWC, Hornatowska J, Salmén L (2013) Experimental micromechanical characterization of wood cell walls. Wood Sci Technol 47:163-182

Faix O, Böttcher JH (1992) The influence of particle-size and concentration in transmission and diffuse reflectance spectroscopy of wood. Holz Roh Werkst 50:221-226

Fengel D, Wegener G (2003) Wood: chemistry, ultrastructure, reactions. Walter de Gruyter, Berlin

Gerhards CC (1982) Effect of moisture content and temperature on the mechanical properties of wood: an analysis of immediate effects. Wood Fiber 14:4-36

Gibson LJ, Ashby MF, Harley BA (2010) Cellular materials in nature and medicine. Cambridge University Press, Cambridge

Gindl W, Teischinger A (2002) Axial compression strength of Norway spruce related to structural variability and lignin content. Compos Part A Appl Sci Manuf 33:1623-1628

Gindl W, Gupta HS, Schöberl T, Lichtenegger HC, Fratzl P (2004) Mechanical properties of spruce wood cell walls by nanoindentation. Appl Phys A 79:2069-2073

Glastrup J, Shashoua Y, Egsgaard H, Mortensen MN (2006) Degradation of PEG in the warship Vasa. Macromol Symp 238:22-29

Håfors B (2001) Conservation of the Swedish warship Vasa from 1628. The Vasa Museum, Stockholm

Hoffmann P (1988) On the stabilization of waterlogged oakwood with polyethylene glycol (PEG) IIItesting the oligomers. Holzforschung 42:289-294

Hoffmann P (2010) On the long-term visco-elastic behavior of polyethylene glycol (PEG) impregnated archaeological oak wood. Holzforschung 46:725-728

CSM Instruments (2002) Overview of mechanical testing standards. Applications Bulletin No. 18, September 2002, CSM Instruments, Peseux, Switzerland

Jäger A, Lackner R, Eberhardsteiner J (2007) Identification of viscoelastic properties by means of nanoindentation taking the real tip geometry into account. Meccanica 42:293-306

Jäger A, Bader TK, Hofstetter K, Eberhardsteiner J (2011) The relation between indentation modulus, microfibril angle and elastic properties of wood cell walls. Compos Part A Appl Sci Manuf Technol 42(6):677-685

Kabel MA, van den Borne H, Vincken JP, Voragen AGJ, Schols HA (2007) Structural differences of xylans affect their interaction with cellulose. Carbohydr Polym 69:94-105

Kato KL, Cameron RE (1999) A review of the relationship between thermally-accelerated ageing of paper and hornification. Cellulose 6:23-40

Konnerth J, Gindl W (2006) Mechanical characterization of wood-adhesive interphase cell walls by nanoindentation. Holzforschung 60:429-433

Konnerth J, Gierlinger N, Keckes J, Gindl W (2009) Actual versus apparent within cell wall variability of nanoindentation results from wood cell walls related to cellulose microfibril angle. J Mater Sci 44:4399-4406

Konnerth J, Eiser M, Jäger A, Bader TK, Hofstetter K, Follrich J, Ters T, Hansmann C, Wimmer R (2010) Macro- and micro-mechanical properties of red oak wood (Quercus rubra L.) treated with hemicellulases. Holzforschung 64:447-453

Lindfors EL, Lindström M, Iversen T (2008) Polysaccharide degradation in waterlogged oak wood from the ancient warship Vasa. Holzforschung 63:57-63

Ljungdahl J (2006) Structure and properties of Vasa oak. Dissertation, KTH Stockholm

Marchessault RH (1962) Applications of infrared spectroscopy to the study of wood polysaccharides. Spectrochim Acta 18:876

Meylan BA (1967) Measurement of microfibril angle by X-ray diffraction. For Prod J 17(5):51-58

Moore AK, Owen NL (2001) Infrared spectroscopic studies of solid wood. Appl Spectrosc Rev 36:65-86

Oliver WC, Pharr GM (1992) An improved technique for determining hardness and elastic modulus using load and displacement sensing indentation experiments. J Mater Res 7:1564-1583

Pauli GF, Jaki BU, Lankin DC (2005) Quantitative H-1 NMR: development and potential of a method for natural products analysis. J Nat Prod 68:133-149

Salmén L, Burgert I (2009) Cell wall features with regard to mechanical performance. A review. Holzforschung 63:121-129

Sandström M, Jalilehvand F, Persson I, Gelius U, Frank P, Hall-Roth I (2002) Deterioration of the seventeenth-century warship Vasa by internal formation of sulphuric acid. Nature 415:893-897 
Smith SA, Langrish TAG (2008) Multicomponent solid modeling of continuous and intermittent drying of Pinus radiata sapwood below the fiber saturation point. Dry Technol 26:844-854

Stamm AJ (1959) Effect of polyethylene glycol treatment upon dimensional stabilization and other properties of wood. For Prod J 9:375-381

Svedström K, Bjurhager I, Kallonen A, Peura M, Serimaa R (2012) Structure of oak wood from the Swedish warship Vasa revealed by X-ray scattering and microtomography. Holzforschung 66:355-363

Tze WTY, Wang S, Rials TG, Pharr GM, Kelley SS (2007) Nanoindentation of wood cell walls: continuous stiffness and hardness measurements. Compos Part A Appl Sci Manuf Technol 38(3):945-953

Vorobyev A, Arnould O, Laux D, Longo R, van Dijk NP, Gamstedt EK (2016) Characterisation of cubic oak specimens from the Vasa ship and recent wood by means of quasi-static loading and resonance ultrasound spectroscopy (RUS). Holzforschung 70(5):457-465

Wagner L, Bader TK, Auty D, de Borst K (2013) Key parameters controlling stiffness variability in trees: a multiscale experimental-numerical approach. Trees 27(1):321-336

Wagner L, Bader TK, de Borst K (2014) Nanoindentation of wood cell walls: effects of sample preparation and processing. J Mater Sci 49(1):94-102

Wagner L, Bos C, Bader TK, de Borst K (2015a) Effect of water on the mechanical properties of wood cell walls-results of a nanoindentation study. BioResources 10(3):4011-4025

Wagner L, Bader TK, Ters T, Fackler K, de Borst K (2015b) A combined view on composition, micromechanics and molecular structure of fungal degraded softwood. Holzforschung 69(4):471-482

Wallström L, Lindberg KAH (1995) Wood surface stabilization with polyethylene glycol, PEG. Wood Sci Technol 29:109-119

Willför S, Sundberg A, Pranovich A, Holmbom B (2005) Polysaccharides in some industrially important hardwood species. Wood Sci Technol 39:601-617

Wimmer R, Lucas BN, Tsui TY, Pharr GM (1997) Longitudinal hardness and Young's modulus of spruce tracheid secondary walls using nanoindentation technique. Wood Sci Technol 31(2):131-141

Zervos S (2010) Natural and accelerated aging of cellulose and paper: a literature review. In: Lejeune A, Deprez T (eds) Cellulose: structure and properties, derivatives and industrial uses. Nova Science, New York, pp 155-203 